\title{
Clinical Consequences of Delayed Addition of Adalimumab to Methotrexate Therapy Over 5 Years in Patients with Rheumatoid Arthritis
}

\author{
EDWARD C. KEYSTONE, ARTHUR KAVANAUGH, MICHAEL E. WEINBLATT, KAUSHIK PATRA, \\ and AILEEN L. PANGAN
}

ABSTRACT. Objective. This Year 5 analysis of an open-label extension (OLE) study assessed radiographic progression, clinical efficacy, and safety of adalimumab with concomitant methotrexate (MTX) for patients with active rheumatoid arthritis.

Methods. In a double-blind study (DE019, NCT00195702), inadequate responders to MTX were randomized to MTX plus either adalimumab $40 \mathrm{mg}$ eow, adalimumab $20 \mathrm{mg}$ weekly, or placebo for 52 weeks. Eligible patients entered an ongoing OLE and received adalimumab $40 \mathrm{mg}$ eow plus MTX. Longterm efficacy and safety were evaluated.

Results. Of 457 patients who had enrolled in the OLE, 304 remained in the study at Year 5, including 112, 107, and 85 from the original adalimumab $40 \mathrm{mg}$, adalimumab $20 \mathrm{mg}$, and placebo groups, respectively. Year 5 radiographs demonstrated mean changes in modified total Sharp score for the original adalimumab $40 \mathrm{mg}$ eow and $20 \mathrm{mg}$ weekly groups of 0.8 and 2.6, respectively, versus 3.9 for placebo; $58 \%$ from the adalimumab $40 \mathrm{mg}$ eow group had no radiographic progression versus $40 \%$ of those who initially received placebo. Of patients who received adalimumab $40 \mathrm{mg}$ eow for 5 years, 26.1\% achieved clinical remission (Disease Activity Score 28-joint count <2.6), had no radiographic progression (change in modified total Sharp score $\leq 0.5$ ), and had normal function (Health Assessment Questionnaire $\leq 0.5$ ), versus $11.9 \%$ of those who initially received placebo. Serious infection rate for 553 patients who received at least one dose of adalimumab was 4.4/100 patient-years.

Conclusion. A 52-week delay in adding adalimumab to MTX led to worse radiographic, functional, and clinical outcomes at Year 5 for most patients who initially received placebo instead of adalimumab. (First Release Feb 1 2011; J Rheumatol 2011;38:855-62; doi:10.3899/jrheum.100752)

Key Indexing Terms:

RHEUMATOID ARTHRITIS RADIOGRAPHIC PROGRESSION

\section{ADALIMUMAB ANTI-TUMOR NECROSIS FACTOR METHOTREXATE CLINICAL REMSSION}

In patients with rheumatoid arthritis (RA), joint erosions may occur within 6 months of disease onset, and progression occurs rapidly within the first 2 years ${ }^{1,2}$. Recognition of

From the Rebecca MacDonald Centre, Mount Sinai Hospital, University of Toronto, Toronto, Ontario, Canada; University of California-San Diego, San Diego, California, USA; Brigham and Women's Hospital, Boston, Massachusetts, USA; and Abbott Laboratories, Abbott Park, Illinois, USA.

Funded by Abbott Laboratories, Abbott Park, IL, USA. Drs. Keystone and Kavanaugh are study investigators for the DE019 trial. Drs. Keystone, Kavanaugh, and Weinblatt have served as Abbott consultants, and have received research grants from Abbott. Drs. Pangan and Patra are employees of Abbott Laboratories, the manufacturer of adalimumab. E.C. Keystone, MD, Rebecca MacDonald Centre, Mount Sinai Hospital, University of Toronto; A. Kavanaugh, MD, University of California-San Diego; M.E. Weinblatt, MD, Brigham and Women's Hospital; K. Patra, PhD; A.L. Pangan, MD, Abbott Laboratories.

Address correspondence to Dr. E.C. Keystone, Division of Advanced Therapeutics, Rebecca MacDonald Centre for Arthritis and Autoimmune Disease, Mount Sinai Hospital, Joseph and Wolf Lebovic Building,

2nd Floor, 60 Murray Street, Toronto, Ontario M5G $1 X 5$.

E-mail: edkeystone@mtsinai.on.ca

Full Release Article. For details see Reprints/Permissions at jrheum.org Accepted for publication December 3, 2010. early radiographic damage has prompted a paradigm shift in RA management, favoring the use of treatments capable of preventing radiographic progression ${ }^{3,4}$.

The primary goals of longterm RA management are to suppress inflammation to the point of clinical remission, prevent structural joint damage, and maintain physical function. Methotrexate (MTX) is the most commonly used disease-modifying antirheumatic drug (DMARD) for RA. Nevertheless, some patients fail to achieve an adequate or sustained response with MTX because of toxicity or lack of efficacy $^{5,6}$. Clinical studies of tumor necrosis factor (TNF) antagonists demonstrate that adding these agents to MTX in patients with inadequate response to MTX has resulted in significant improvement in clinical signs and symptoms and physical function $3,7,8,9,10,11$. Further, TNF antagonist therapy results in approximately $80 \%-90 \%$ inhibition of radiographic progression, as measured by mean changes in modified total Sharp score (mTSS), compared with MTX alone in 1 -year studies ${ }^{8,9}$. Control of joint damage, sustained clinical remission, and maintenance of physical function have been viewed as the hallmarks of comprehensive treatment

Personal non-commercial use only. The Journal of Rheumatology Copyright $\subset$ C 2011. All rights reserved. 
benefit for patients with RA. What remains to be confirmed is the ability of anti-TNF therapy to sustain these 3 outcomes over the long term.

Several clinical trials of RA patients demonstrated clinical and radiographic efficacy and safety of adalimumab in combination with standard antirheumatic therapy, including MTX $^{9,10,12,13,14,15,16}$, and as monotherapy ${ }^{17}$. In a randomized controlled study of patients with established RA who had an inadequate response to initial treatment with MTX (DE019), adalimumab plus MTX was significantly more effective than MTX alone in reducing clinical signs and symptoms, improving physical function, and inhibiting radiographic disease progression ${ }^{9}$. At Week 52, a 20\% improvement in American College of Rheumatology score (ACR20 response) was achieved by 59\% and 55\% of patients receiving adalimumab $40 \mathrm{mg}$ every other week (eow) plus MTX, or adalimumab $20 \mathrm{mg}$ weekly plus MTX, respectively, compared with $24 \%$ of patients receiving MTX alone ( $\mathrm{p} \leq 0.001$ for each comparison). Significant improvements were also observed in physical function as measured by Health Assessment Questionnaire Disability Index (HAQ DI). In addition, significant inhibition of radiographic progression, as measured by the change in mTSS, was observed for patients receiving adalimumab $40 \mathrm{mg}$ eow plus MTX (mean change in mTSS $\pm \mathrm{SD}, 0.1 \pm 4.8$ ) or adalimumab 20 mg weekly plus MTX $(0.8 \pm 4.9)$, compared with patients receiving MTX alone $(2.7 \pm 6.8)(\mathrm{p} \leq 0.001$ for each comparison).

This report presents 5-year data from the ongoing open-label extension (OLE) of the DE019 study, which evaluated the safety and efficacy of longterm treatment with adalimumab plus MTX in patients with prior inadequate response to MTX.

\section{MATERIALS AND METHODS}

Patients. Patients enrolled in the original double-blind phase of DE019 were age 18 years or older, had a diagnosis of RA as defined by the 1987 revised ACR criteria ${ }^{18}$, and had active disease despite MTX therapy for at least 3 months, with stable dosages of 12.5 to $25 \mathrm{mg} /$ week for at least 4 weeks (or $\geq 10 \mathrm{mg} /$ week for those intolerant of MTX) ${ }^{9}$. They also had a tender joint count (TJC) of $\geq 9$ (of 68 joints evaluated), a swollen joint count (SJC) $\geq 6$ (of 66 joints evaluated), a C-reactive protein (CRP) concentration $>1 \mathrm{mg} / \mathrm{dl}$, and either rheumatoid factor positivity or at least 1 joint erosion on radiographs of the hands and feet.

Treatment. In the 52-week, double-blind study (DE019, NCT00195702), patients were randomized to receive adalimumab $40 \mathrm{mg}$ subcutaneously eow, adalimumab $20 \mathrm{mg}$ subcutaneously weekly, or placebo. All patients received concomitant MTX. Patients who completed the 52-week double-blind study were eligible to enter the ongoing OLE phase. During the OLE, which continues to Year 10, all patients receive adalimumab $40 \mathrm{mg}$ eow plus MTX. All patients who reached Year 5 of the OLE phase had received at least 4 years of exposure to adalimumab $40 \mathrm{mg}$ eow except for patients who were originally randomized to adalimumab $40 \mathrm{mg}$ eow during the double-blind period who had 5 years of adalimumab 40 eow therapy. Those originally randomized to $20 \mathrm{mg}$ weekly or placebo had 1 year of this blinded therapy and 4 years of adalimumab 40 eow.

The objectives of the OLE of DE019 were to evaluate the longterm maintenance of clinical and radiographic efficacy and safety of adalimum- ab in patients with moderate to severe RA receiving concurrent MTX therapy.

Efficacy assessments

Clinical assessments. For clinical signs and symptoms of RA and changes in physical function, efficacy over time was evaluated and analyzed as observed values by duration of exposure to adalimumab (whether blinded or open-label). Exposure for an individual patient was calculated by determining the number of days between the first and last drug dose and adding 14 days, which was the time interval between doses of adalimumab in the OLE. Baseline values for clinical and functional assessments were defined as the most recent assessment prior to a patient's first adalimumab injection. For patients originally assigned to adalimumab therapy during the double-blind period, baseline values were obtained at the beginning of study Year 1. Conversely, for patients randomized to placebo in the double-blind period, baseline values were obtained immediately prior to the start of the OLE phase (i.e., beginning of study Year 2).

ACR20/ACR50/ACR70 responses were assessed at each post-baseline visit. Additional clinical efficacy endpoints examined include the 28-joint count Disease Activity Score (DAS28) ${ }^{19}$. In addition, physical function was assessed at baseline and at each subsequent visit using the HAQ $\mathrm{DI}^{20}$.

Radiographic assessment. For radiographic results, data are presented by original randomized treatment group at absolute study timepoints, at baseline and Years 1, 3, and 5 of the study. Radiographs for patients who had reached Year 5 were included in the analysis, as were radiographs for those patients who discontinued between Years 3 and 5. Presenting radiographic progression by randomized treatment group was necessary because patients were more comparable in terms of radiographic damage at study Week 0 (baseline or start of Year 1) versus any subsequent timepoint. Radiographic damage that may have occurred in any group during the year of double-blind treatment could possibly affect overall outcomes, even after all patients were switched to adalimumab $40 \mathrm{mg}$ eow in the OLE. In addition, this approach allowed for evaluation of the influence of switching to adalimumab $40 \mathrm{mg}$ eow plus MTX in the OLE on the progression of structural damage for those patients who had initially received placebo and MTX during the double-blind period. No statistical hypotheses were tested.

Radiographs were assessed using a modified version of the Sharp scoring method by 2 physicians blinded to treatment, chronologic order, and clinical response. To ensure consistent readings, the evaluators reread the radiographs as a group for baseline and Years 1,3, and 5. In determination of the mTSS score for each patient, the total joint erosion score (0-230) and the total joint space narrowing score $(0-168)$ were summed $(0-398)$. These assessments are described in detail in the original report of the double-blind phase of DE019.

Comprehensive disease remission. The percentage of patients who achieved comprehensive disease remission at Year 5 was determined. This was defined as the concurrent presence of the following triple criteria: clinical remission (DAS28 < 2.6), normal physical function (HAQ $\leq 0.5$ ), and radiographic nonprogression (change from baseline $\mathrm{mTSS} \leq 0.5$ ).

Safety assessments. Safety assessments included records of adverse events (AE), physical examinations, and standard laboratory tests. Patients were monitored for $\mathrm{AE}$ throughout the entire study. A treatment-emergent $\mathrm{AE}$ was defined as an $\mathrm{AE}$ with onset date on or after first adalimumab injection up to 70 days (5 half-lives) after last dose received. Patient-years of exposure to adalimumab were calculated by determining the number of days of exposure for each patient, and then summing the days of exposure for all patients and dividing the total by 365.25 .

Statistical analyses. All patients who received at least one dose of adalimumab, whether as blinded or open-label therapy, were included in all safety and efficacy analyses. Data were analyzed through descriptive statistics alone, and no statistical comparisons were conducted.

\section{RESULTS}

Patient disposition. Of the 619 patients initially randomized Personal non-commercial use only. The Journal of Rheumatology Copyright $\subset$ 2011. All rights reserved. 
in the double-blind portion of DE019, 467 completed the 52-week double-blind period; 457 (158, 165, and 134 patients originally randomized to adalimumab $40 \mathrm{mg}$ eow, adalimumab $20 \mathrm{mg}$ weekly, and placebo, respectively) entered the OLE. A total of 553 patients received at least one dose of adalimumab, either as blinded or open-label therapy ("all-adalimumab analysis set"; Figure 1). For these 553 patients, mean exposure to adalimumab was 3.3 years (median $3.9 \mathrm{yrs}$ ). In addition, 304 patients are continuing in the OLE past Year 5, including 112 from the original adalimumab $40 \mathrm{mg}$ eow group, 107 from the adalimumab $20 \mathrm{mg}$ weekly group, and 85 from the placebo group.
Of the 553 patients who received at least one injection of adalimumab, 212 received their first injections of adalimumab during the double-blind portion of DE019 at a dose of $20 \mathrm{mg}$ weekly; 207 received their first injections during the double-blind portion at a dose of $40 \mathrm{mg}$ eow; and 134 patients who received placebo during the double-blind period received their first injections of adalimumab (at a dosage of $40 \mathrm{mg}$ eow) following entry into the OLE.

Demographics and baseline characteristics. Baseline demographics and disease characteristics (based on the most recent assessment prior to the first adalimumab injection, whether blinded or open-label) for the 553 patients in the

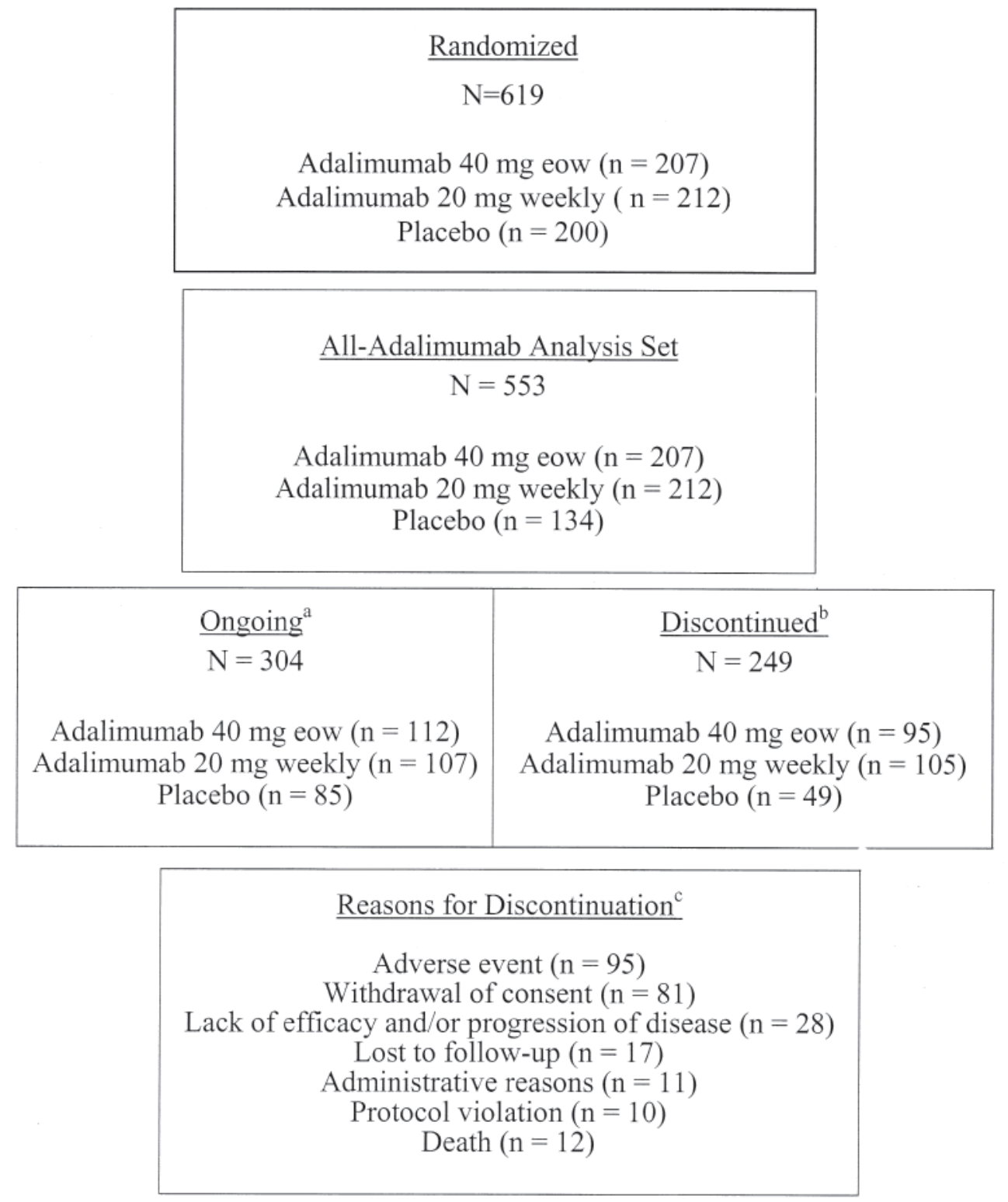

Figure 1. Disposition of patients in the 5-year open-label extension of DE019. ${ }^{\mathrm{a}}$ Ongoing as of Year 5. bPatients who discontinued from the study while receiving either blinded or open-label adalimumab. Patients originally randomized to placebo who did not receive open-label adalimumab are not included. 'Patients may have had more than one reason for discontinuation. 
all-adalimumab analysis set were similar to those observed for the original study sample $(\mathrm{n}=619 \text {; Table } 1)^{9}$. However, baseline disease activity, as measured by TJC, SJC, patient's global assessment of pain, patient's global assessment of disease activity, and physician's global assessment of disease activity, was slightly lower but still indicative of active RA. This is primarily due to patients from the placebo group having lower baseline disease activity measures/scores assessed just prior to the first open-label adalimumab dose compared to their original double-blind baseline values.

Clinical signs and symptoms of RA and physical function. Regardless of when patients first received adalimumab, either in the double-blind period or its OLE, by Week 2 of treatment, $30 \%$ of patients had achieved an ACR20 response (Figure 2A). Peak response was observed by Week 20 and was sustained through 260 weeks of adalimumab exposure. ACR50 and ACR70 response rates were also sustained over time. At the end of 5 years, $75 \%, 58 \%$, and $35 \%$ of the 219 patients who had received 5 years of adalimumab treatment achieved ACR20, ACR50, and ACR70 responses rates, respectively. Similarly, the percentage of patients achieving DAS28 clinical remission (DAS28 < 2.6) was sustained over time. Of patients who had received 5 years of adalimumab therapy (Figure 2B), 45\% had achieved DAS28 clinical remission, $36 \%$ had a TJC-68 of 0 , and $28 \%$ had an SJC-66 of 0. Similarly, among patients in the original placebo group who have received 4 years of adalimumab therapy

Table 1. Demographics and baseline disease characteristics of patients with rheumatoid arthritis who received adalimumab at any time during the blinded period or open-label extension of Study DE019 $(\mathrm{N}=553)$. Values are mean (SD) unless otherwise stated.

\begin{tabular}{lc}
\hline Characteristics & Mean (SD) \\
\hline Age, yrs & $55.7(12.0)$ \\
Female, $\%$ & 74.7 \\
Disease duration, yrs & $10.9(9.0)$ \\
Methotrexate use, $\%$ & 100 \\
Oral corticosteroid use, \% & 50.8 \\
Tender joint count (0-68 joints) & $24.8(14.4)$ \\
Swollen joint count (0-66 joints) & $17.7(10.4)$ \\
Patient global assessment of pain (0-100 mm VAS)* & $51.4(23.0)$ \\
Patient's global assessment of disease activity & \\
$\quad(0-100$ mm VAS)* & $48.7(23.1)$ \\
Physicians global assessment of disease activity & $55.4(21.2)$ \\
(0-100 mm VAS)* & $1.4(0.7)$ \\
HAQ DI (0-3 scale) $)^{\dagger}$ & $5.4(1.1)$ \\
DAS28 & $1.7(1.7)$ \\
C-reactive protein, mg/dl & \\
\hline
\end{tabular}

*VAS for pain ranges from $0=$ no pain to $100=$ severe pain; VAS for disease activity ranges from $0=$ no disease activity to $100=$ extreme disease activity. ${ }^{\dagger}$ HAQ DI scale ranges from $0=$ no difficulty to $3=$ unable to perform activity. ${ }^{\dagger}$ DAS28 is based on a 28 -joint assessment for pain or swelling using the C-reactive protein-based formula available from: (www.das-score.nl/www.das-score.nl/index.html). DAS: disease activity score; HAQ DI: Health Assessment Questionnaire Disability Index; VAS: visual analog scale.
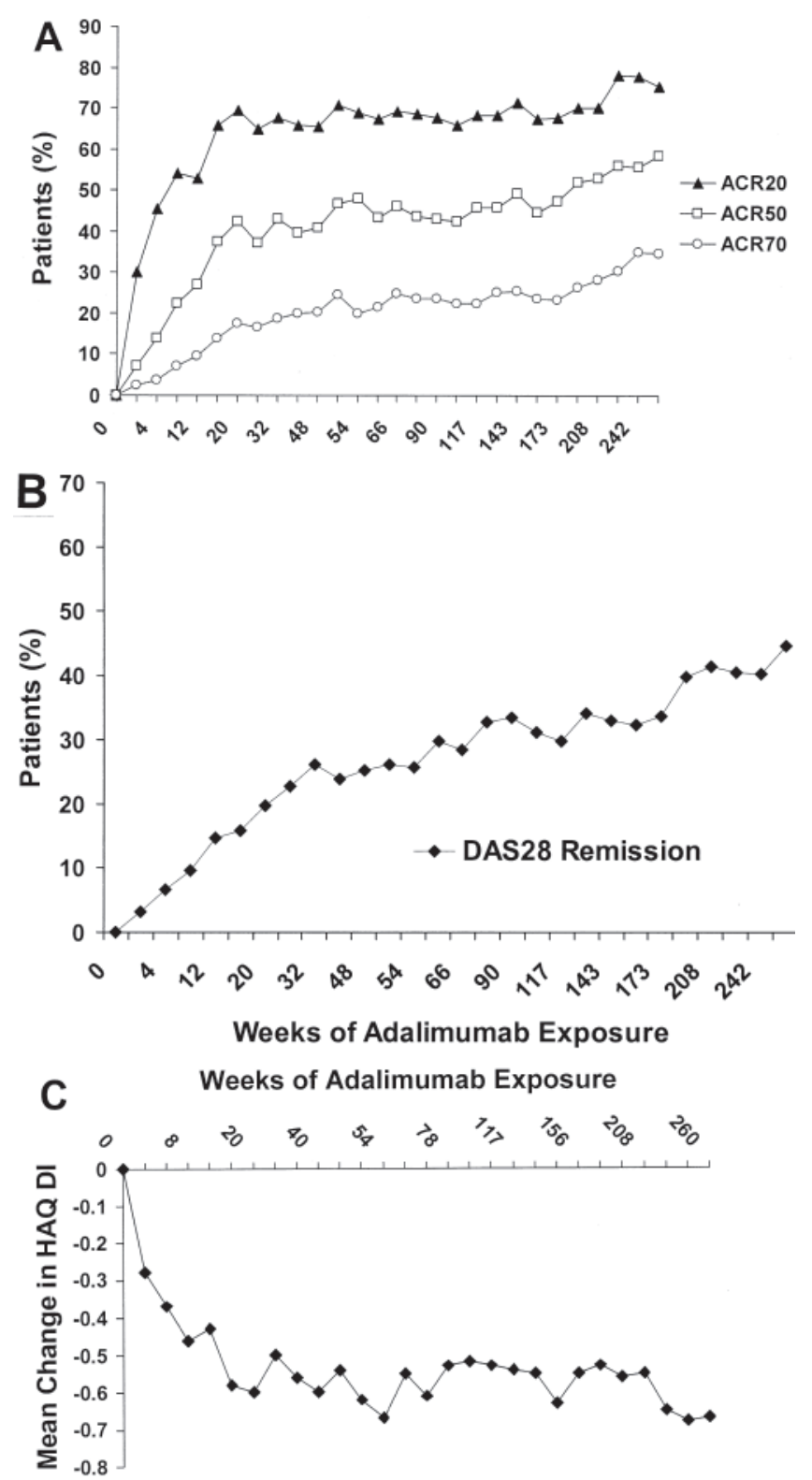

Figure 2. Effect of adalimumab on clinical signs and symptoms and physical function associated with rheumatoid arthritis (RA). A. Percentages of patients with RA receiving adalimumab plus methotrexate (MTX) who showed 20\%, 50\%, and 70\% improvement in American College of Rheumatology (ACR) response criteria over time. Percentage based on total non-missing response for individual timepoints. B. Percentage of patients with RA receiving adalimumab plus MTX achieving DAS28 clinical remission over time. C. Mean changes in Health Assessment Questionnaire Disability Index (HAQ DI) by adalimumab exposure over time.

by Year 5, 46\% achieved DAS28 remission, 31\% had a TJC-68 of 0 , and 34\% had an SJC-66 of 0 .

Improvements in physical function, as measured by mean changes in HAQ DI, were observed as early as 2 weeks after the first adalimumab dose (Figure 2C). Improvements of $\geq$ -0.22 , the minimum clinically important difference (MCID) Personal non-commercial use only. The Journal of Rheumatology Copyright @ 2011 . All rights reserved. 
for HAQ DI response 21 , were consistently observed throughout 5 years of adalimumab exposure. The mean HAQ DI $( \pm$ SD) score for patients with 5 years of adalimumab treatment was $0.7( \pm 0.7)$ compared with $1.4( \pm 0.6)$ at baseline. For the original placebo group, the mean HAQ DI $( \pm$ SD) score at Year 5 was $0.8( \pm 0.7)$.

Radiographic progression. Radiographic analyses were performed for patients for whom radiographic data were available at baseline and Years 1, 3, and 5, and presented based on original randomized treatment arms. Baseline mean mTSS for the patients with Year 5 radiographs were lower for those from the original placebo group: adalimumab 40 mg eow + MTX $(n=113,68.6)$, adalimumab 20 mg weekly + MTX ( $\mathrm{n}=107,68.6)$, and placebo + MTX $(n=86$, 56.0). Patients who were originally treated with placebo and then switched to adalimumab in the OLE experienced a slower rate of disease progression at their Year 3 and Year 5 visits, compared with their Year 1 visits. However, the delayed start of adalimumab after 1 year of placebo still led to worse radiographic outcomes at Year 5 compared with patients who were started on adalimumab $40 \mathrm{mg}$ eow plus MTX at the beginning of the double-blind study. At Year 5, the mean $( \pm$ SD) changes from baseline in mTSS for patients who received adalimumab $40 \mathrm{mg}$ eow plus MTX and those treated with adalimumab $20 \mathrm{mg}$ weekly plus MTX were 0.8 \pm 10.6 and $2.6 \pm 9.6$, respectively, versus $3.9 \pm 9.8$ for patients receiving placebo plus MTX (Figure 3A). Similar results were observed for joint erosion and joint space narrowing scores at Years 1, 3, and 5, with the original adalimumab $40 \mathrm{mg}$ eow plus MTX group experiencing the best radiographic outcomes at Year 5 (Figures 3B and 3C). These results also demonstrate that the mean change of 0.8 for the original adalimumab $40 \mathrm{mg}$ eow plus MTX group was largely driven by the mean change in the joint space narrowing score (0.9), as the joint erosion score was virtually unchanged (mean change of -0.1 ).

At 5 years, $58 \%(66 / 113)$ of the patients from the original adalimumab $40 \mathrm{mg}$ eow plus MTX treatment group had no radiographic progression (change in mTSS $\leq 0.5$ ) compared with $44 \%$ (47/107) of the patients originally from the $20 \mathrm{mg}$ weekly plus MTX group and 40\% (34/86) from the placebo plus MTX group (Figure 4). At all 3 timepoints, there were more patients with radiographic progression (change in mTSS $>0.5$ ) and with change in mTSS $>5$ units in the original placebo plus MTX group compared with the adalimumab $40 \mathrm{mg}$ eow plus MTX group.

Triple-variable measure of comprehensive disease remission. Of patients with available data at the Year 5 timepoint, similar percentages of patients in the original adalimumab $40 \mathrm{mg}$ eow plus MTX arm and in the placebo plus MTX arm were in DAS28 clinical remission $(<2.6)$ : $45.1 \%$ versus $45.9 \%$. However, when DAS28 clinical remission and normal function $(\mathrm{HAQ} \leq 0.5)$ were both required, the response rate was higher for patients in the original adalimumab
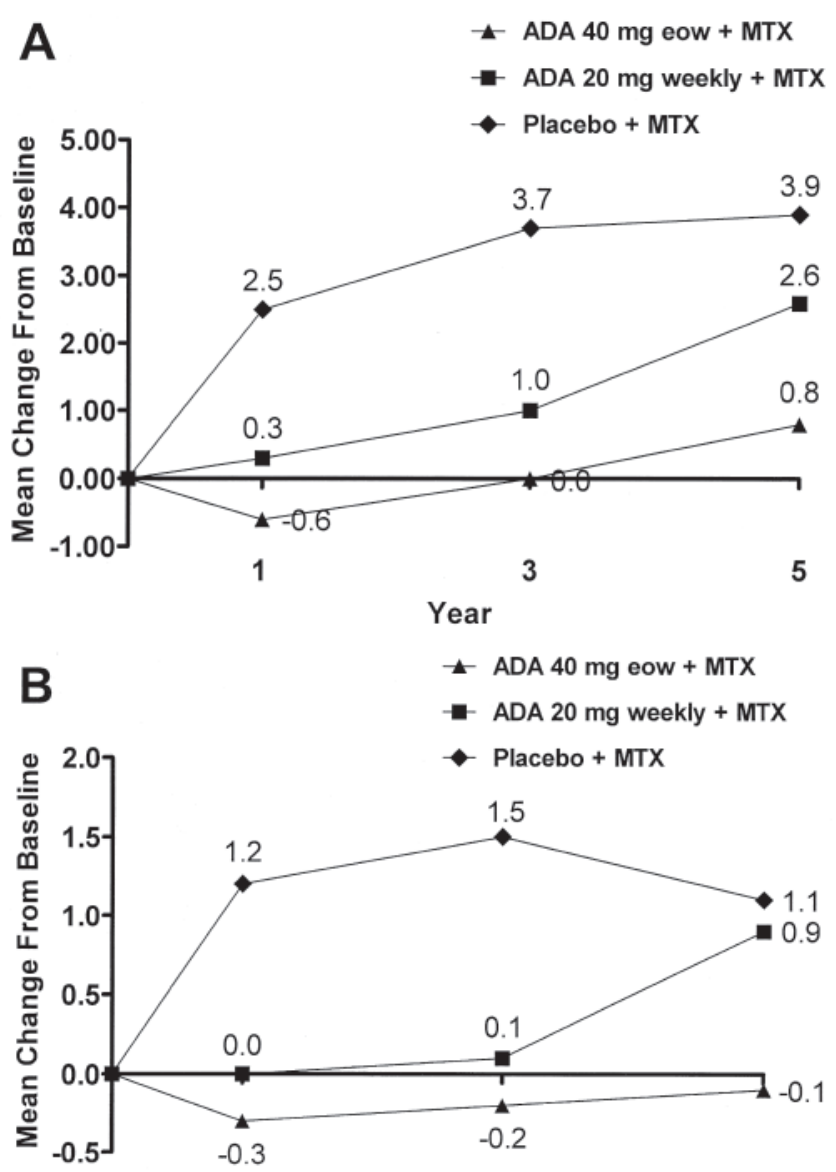

1

3

5

Year

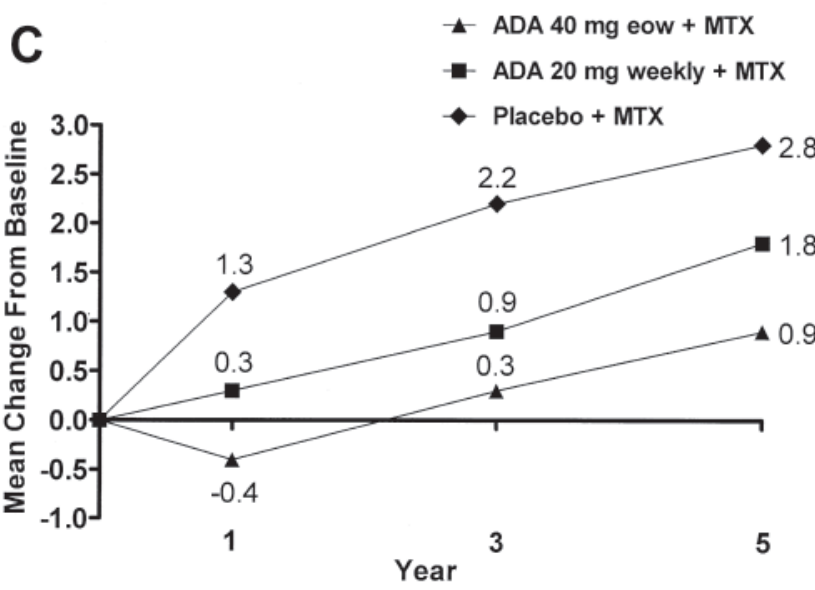

Figure 3. Radiographic progression over 5 years by randomized group and study year. A. Mean change from baseline in total Sharp scores over time. B. Mean change from baseline in erosion scores over time. C. Mean change from baseline in joint-space narrowing scores over time. Positive change indicates progression. ADA: adalimumab; eow: every other week; MTX: methotrexate.

$40 \mathrm{mg}$ eow group: $35.4 \%$ versus $28.2 \%$. Finally, the concurrent presence of DAS28 clinical remission, normal physical function, and radiographic nonprogression (mean change in

$$
\text { Personal non-commercial use only. The Journal of Rheumatology Copyright (C) 2011. All rights reserved. }
$$




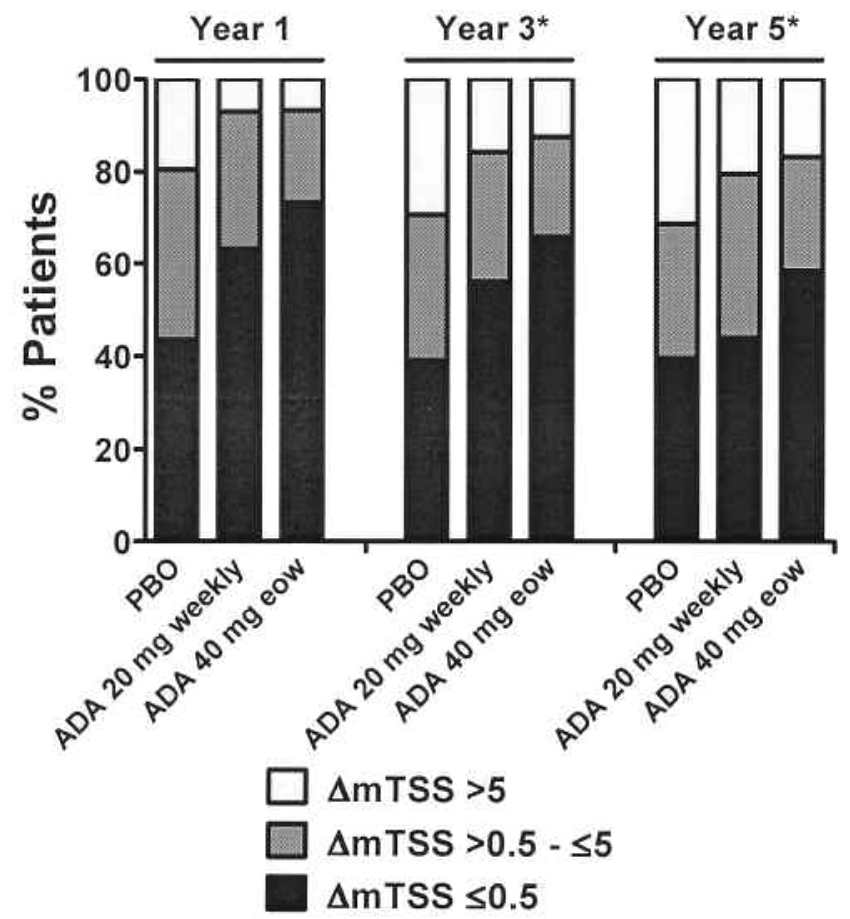

Figure 4. Subsets of radiographic progresssors and non-progressors over 5 years by randomized group and study year. Patients were receiving background methotrexate (MTX) throughout the study. *Data based on original randomized group; all patients received open-label adalimumab (ADA) beyond Year 1. eow: every other week; mTSS: modified total Sharp score; PBO: placebo.

mTSS $\leq 0.5$ ) was observed in $26.1 \%$ of the original adalimumab $40 \mathrm{mg}$ eow group versus $11.9 \%$ in the original placebo group.

Longterm safety. A total of 553 patients received at least one dose of adalimumab and were included in the safety analysis. Collectively, these patients accounted for $1,824.3$ patient-years of exposure to adalimumab. Serious infections occurred at the rate of 4.4 events per 100-patient-years. Two cases of tuberculosis were reported. The rate for malignancies other than non-melanoma skin cancer was 1.5/100-patient-years, and the rate for non-melanoma skin cancers was 1.1/100-patient-years. Twelve deaths occurred during the 5-year clinical trial: 2 associated with a malignancy (one of which was a B-cell lymphoma), 3 associated with an infection, 3 were due to trauma or chemical poisoning, and 4 were due to various medical conditions.

\section{DISCUSSION}

Synovial inflammation and bone erosions both contribute to functional disability in RA to varying degrees depending on the stage of the disease $\mathrm{e}^{22,23}$. The correlation of disease activity with functional disability remains stable over time, but the correlation of radiographic damage with decreased functionality increases over the course of $\mathrm{RA}^{24}$. Treatment goals, therefore, include sustained control of active inflammation and inhibition of radiographic progression, both of which lead to improvement and maintenance of function ${ }^{2,4,25}$.

The 52-week results of the double-blind randomized controlled trial DE019 demonstrated that, for patients with RA who had an inadequate response to MTX, the addition of adalimumab led to better clinical responses and greater inhibition of structural damage compared with patients who continued with MTX monotherapy. This illustrates a window of opportunity to effect a considerable change in a patient's disease course when persistent disease activity with MTX monotherapy is observed and anti-TNF therapy, such as adalimumab, may be added to achieve better control. The question of whether this benefit is sustained and if delay in the addition of an anti-TNF agent in MTX inadequate responders contributes to the longterm outcome in RA is addressed by the results of this 5-year report of the open-label extension of DE019.

Patients generally tolerated continued adalimumab therapy, with more than $50 \%$ of the patients who had started adalimumab $40 \mathrm{mg}$ eow plus MTX $(\mathrm{n}=207)$ remaining on the same regimen for 5 years $(n=112)$. Improvements in the clinical signs and symptoms of RA, as measured by ACR and DAS28 responses, and physical function, as measured by the HAQ DI, were sustained through 5 years of adalimumab therapy. The percentages of patients who achieved DAS28 clinical remission were relatively similar for both the original adalimumab $40 \mathrm{mg}$ eow and placebo treatment groups by Year 5. However, there is a selection bias for patients from the original placebo group who were able to complete 52 weeks of placebo and enter the OLE. These patients likely represent a less refractory subset who tend to do better and still have some level of clinical response despite being on placebo plus background MTX. Nonetheless, the similarity in clinical remission response rates alludes to the effectiveness of adalimumab in controlling signs and symptoms of RA regardless of when therapy is initiated.

The argument that there is a clinical consequence to delaying better control of RA with appropriate therapy is evident by examination of the efficacy outcomes that reflect potential irreversible damage. Although DAS28 clinical remission rates were the same between the adalimumab $40 \mathrm{mg}$ eow and placebo groups at Year 5, when the attainment of normal functionality was added to the response criteria, the adalimumab $40 \mathrm{mg}$ eow group had better results. The difference between the 2 treatment groups was further amplified when the absence of radiographic progression was also taken into account (comprehensive disease remission). The greater radiographic damage accrued by patients in the original placebo plus MTX arm over the course of 1 year puts them at a disadvantage even after they had switched to open-label adalimumab therapy for up to 4 years, compared with patients who began combination therapy with adalimumab plus MTX at the initiation of the trial. The rate of

Personal non-commercial use only. The Journal of Rheumatology Copyright $@$ (2011. All rights reserved. 
radiographic progression did slow down for the original placebo group in the open-label period, becoming nearly parallel to the original adalimumab groups. However, irreversible damage, unyielding to subsequent better therapy with adalimumab plus MTX ${ }^{26,27,28}$, could have led to the overall worse outcome at Year 5 for the majority of patients originally randomized to placebo compared with those in the adalimumab $40 \mathrm{mg}$ eow group. Radiographic progression for the original adalimumab $20 \mathrm{mg}$ weekly group is somewhere between that of the placebo and the adalimumab $40 \mathrm{mg}$ eow groups. The optimal and approved dose of adalimumab for RA is $40 \mathrm{mg}$ eow. The $20 \mathrm{mg}$ weekly dose may not have been as effective as $40 \mathrm{mg}$ eow but was still better than placebo.

An interesting observation from the evaluation of Year 5 radiographs for the adalimumab $40 \mathrm{mg}$ eow plus MTX group was that, although the mean joint erosion score was unchanged (mean change -0.1), there was a slight increase in joint space narrowing (mean change 0.9), although to a lesser degree than that seen in the other treatment arms. TNF promotes the activation, proliferation, and differentiation of osteoclast precursor cells into mature osteoclasts, which mediate erosion of bone in $\mathrm{RA}^{29,30,31}$. TNF has also been implicated in the release of matrix metalloproteinases and specific proteins from the ADAMTS (a disintegrin-like and metalloproteinase with thrombospondin motifs) family, and in the suppression of cartilage matrix synthesis, both processes contributing to cartilage destruction in $\mathrm{RA}^{32,33,34}$. Therefore, effective TNF blockade can potentially slow or halt both the bone erosive process and cartilage destruction in RA. The small increase in joint space narrowing observed over 5 years in DE019 may be attributed to changes within the joint as a result of either the sequelae of prior bone and cartilage damage due to RA or, in some joints, coexisting degenerative joint disease ${ }^{22,23,35}$. In patients with early RA, the combination of adalimumab plus MTX resulted in similar inhibition of joint erosion and joint space narrowing over 2 years mean change of 1.0 and 0.9 units, respectively ${ }^{16}$. What remains to be addressed is whether or not earlier use of anti-TNF therapy with MTX prior to the onset of significant bone and cartilage damage can result in prevention of both joint erosions and joint space narrowing.

Safety data from this 5-year report of DE019 are consistent with the longterm data reported for the larger RA clinical trial population with adalimumab ${ }^{36}$. Thus, the combination of longterm clinical and safety data supports a favorable risk-benefit profile for adalimumab in patients with established RA who continue to have active disease with MTX.

The limitations of this analysis include those typical of other open-label extension studies. There is a selection bias for patients who are doing well to remain in the study. Therefore, data are available for a smaller group of patients compared to the original randomized population. In an observed data analysis, this results in slightly increased per- centages of patients obtaining high levels of clinical response toward the latter part of the study.

In summary, the 5-year results from the DE019 study provided the following insights regarding established RA: (1) Clinical and functional improvements observed with adalimumab plus MTX in a double-blind fashion are sustained with continued open-label adalimumab plus MTX therapy up to a total of 5 years; and (2) For the majority of patients, delaying tighter disease control with the addition of more potent agents, such as anti-TNF therapy, when MTX does not adequately control RA, can result in continued structural damage that lessens the likelihood of patients achieving longterm, comprehensive disease control (i.e., clinical remission, radiographic nonprogression, and normal function). The availability of highly effective anti-TNF therapies should enable physicians to offer patients with RA an opportunity to better manage signs and symptoms and alter the progressive course of this disease.

\section{ACKNOWLEDGMENT}

The authors thank Michael A. Nissen, ELS, of Abbott Laboratories, Abbott Park, IL, USA, for medical writing and editing support in the development and revision of this report. This support was funded by Abbott.

\section{REFERENCES}

1. Lindqvist E, Jonsson K, Sazne T, Eberhardt K. Course of radiographic damage over 10 years in a cohort with early rheumatoid arthritis. Ann Rheum Dis 2003;62:611-6.

2. van der Heijde DMFM. Joint erosions and patients with early rheumatoid arthritis. Br J Rheumatol 1995;34 Suppl 2:74-8.

3. Breedveld FC, Kalden JR. Appropriate and effective management of rheumatoid arthritis. Ann Rheum Dis 2004;63:627-33.

4. American College of Rheumatology Subcommittee on Rheumatoid Arthritis Guidelines. Guidelines for the management of rheumatoid arthritis: 2002 update. Arthritis Rheum 2002;46:328-46.

5. Kremer JM. Rational use of new and existing disease-modifying agents in rheumatoid arthritis. Ann Intern Med 2001;134:695-706.

6. Kremer JM. Safety, efficacy, and mortality in a long-term cohort of patients with rheumatoid arthritis taking methotrexate: follow-up after a mean of 13.3 years. Arthritis Rheum 1997;40:984-5.

7. Emery P. Treatment of rheumatoid arthritis. BMJ 2006;332:152-5.

8. Lipsky P, van der Heijde D, St. Clair E, Furst DE, Breedveld FC, Kalden JR, et al. Infliximab and methotrexate in the treatment of rheumatoid arthritis: antitumor necrosis factor trial in rheumatoid arthritis with concomitant therapy group. N Engl J Med 2000;343:1594-602.

9. Keystone EC, Kavanaugh AF, Sharp JT, Tannenbaum H, Hua Y, Teoh LS, et al. Radiographic, clinical and functional outcomes with adalimumab (a human anti-TNF monoclonal antibody) in the treatment of patients with active rheumatoid arthritis on concomitant methotrexate therapy: a randomized, placebo-controlled, 52-week trial. Arthritis Rheum 2004;50:1400-11.

10. Weinblatt ME, Keystone EC, Furst DE, Moreland LW, Weisman MH, Birbara CA, et al. Adalimumab, a fully human anti-tumor necrosis factor alpha monoclonal antibody, for the treatment of rheumatoid arthritis in patients taking concomitant methotrexate: the ARMADA Trial. Arthritis Rheum 2003;48:35-45.

11. Weinblatt ME, Kremer JM, Bankhurst AD, Bulpitt KJ, Fleischmann RM, Fox RI, et al. A trial of etanercept, a recombinant tumor

Personal non-commercial use only. The Journal of Rheumatology Copyright $\odot$ 2011. All rights reserved. 
necrosis factor receptor:Fc fusion protein, in patients with rheumatoid arthritis receiving methotrexate. N Engl J Med 1999; 340:253-9.

12. Furst DE, Schiff MH, Fleischmann RM, Strand V, Birbara CA, Compagnone D, et al. Adalimumab, a fully human anti-tumor necrosis factor monoclonal antibody, and concomitant standard antirheumatic therapy for the treatment of rheumatoid arthritis: results of STAR (Safety Trial of Adalimumab in Rheumatoid Arthritis). J Rheumatol 2003;30:2563-71.

13. Rau R, Simianer S, van Riel PLCM, van de Putte LBA, Krüger K, Schattenkirchner M, et al. Rapid alleviation of signs and symptoms of rheumatoid arthritis with intravenous or subcutaneous administration of adalimumab in combination with methotrexate. Scand J Rheumatol 2004;33:145-53.

14. Weinblatt ME, Keystone EC, Furst DE, Kavanaugh AF, Chartash EK, Segurado OG. Long term efficacy and safety of adalimumab plus methotrexate in patients with rheumatoid arthritis: ARMADA 4 year extended study. Ann Rheum Dis 2006;65:753-9.

15. Weisman M, Moreland L, Furst D, Weinblatt ME, Keystone EC, Paulus HE, et al. Efficacy, pharmacokinetic, and safety assessment of adalimumab, a fully human anti-tumor necrosis factor-alpha monoclonal antibody, in adults with rheumatoid arthritis receiving concomitant methotrexate: a pilot study. Clin Ther 2003;25:1700-21.

16. Breedveld FC, Weisman MH, Kavanaugh AF, Cohen SB, Pavelka $\mathrm{K}$, van Vollenhoven R, et al. The PREMIER study: A multicenter, randomized, double-blind clinical trial of combination therapy with adalimumab plus methotrexate versus methotrexate alone or adalimumab alone in patients with early, aggressive rheumatoid arthritis who had not had previous methotrexate treatment. Arthritis Rheum 2006;54:26-37.

17. van de Putte LBA, Atkins C, Malaise M, Sany J, Russell AS, van Riel PLCM, et al. Efficacy and safety of adalimumab as monotherapy in patients with rheumatoid arthritis who have failed previous disease-modifying antirheumatic drug therapy. Ann Rheum Dis 2004;63:508-16.

18. Arnett FC, Edworthy SM, Bloch DA, McShane DJ, Fries JF, Cooper NS, et al. The American Rheumatism Association 1987 revised criteria for the classification of rheumatoid arthritis. Arthritis Rheum 1988;31:315-24.

19. Prevoo ML, van t 'Hof MA, Kuper HH, van Leeuwen MA, van de Putte LB, van Riel PL. Modified disease activity scores that include twenty-eight-joint counts. Development and validation in a prospective longitudinal study of patients with rheumatoid arthritis. Arthritis Rheum 1995;38:44-8.

20. Fries JF, Spitz PW, Young DY. The dimensions of health outcomes: the Health Assessment Questionnaire, disability and pain scales. J Rheumatol 1982;9:789-93.
21. Goldsmith C, Boers M, Bombardier C, Tugwell P. Criteria for clinically important changes in outcomes: development, scoring and evaluation of rheumatoid arthritis patient and trial profiles. J Rheumatol 1993;20:561-5.

22. Kirwan JR. Links between radiological change, disability, and pathology in rheumatoid arthritis. J Rheumatol 2001;28:881-6.

23. Kirwan JR. Conceptual issues in scoring radiographic progression in rheumatoid arthritis. J Rheumatol 1999;26:720-5.

24. Drossaers-Bakker KW, de Buck M, van Zeben D, Zwinderman AH, Breedveld FC, Hazes JM. Long-term course and outcome of functional capacity in rheumatoid arthritis: the effect of disease activity and radiologic damage over time. Arthritis Rheum 1999;42:1854-60.

25. McInnes IB, Jacobs JWG, Woodburn J, van Laar JM. Treatment of rheumatoid arthritis. In: Bijlsma JWJ, Burmester GR, da Silva JAP, Faarvang KL, Hachulla E, Mariette X, editors. EULAR compendium on rheumatic diseases. London: BMJ Publishing Group Ltd.; 2009:81-91.

26. Aletaha D, Smolen J, Ward MH. Measuring function in rheumatoid arthritis: Identifying reversible and irreversible components. Arthritis Rheum 2006;54:2784-92.

27. Smolen JS, Aletaha D, Steiner G. Does damage cause inflammation? Revisiting the link between joint damage and inflammation. Ann Rheum Dis 2009:68:159-62.

28. Smolen JS, Aletaha Grisar JC, Stamm TA, Sharp JT. Estimation of a numerical value for joint damage-related physical disability in rheumatoid arthritis clinical trials. Ann Rheum Dis 2010;69:1058-64.

29. Choy EH, Panayi GS. Cytokine pathways and joint inflammation in rheumatoid arthritis. N Engl J Med 2001;344:907-16.

30. McInnes IB, Schett G. Cytokines in the pathogenesis of rheumatoid arthritis. Nat Rev Immunol 2007;7:429-42.

31. Redlich K, Hayer S, Ricci R, David JP, Tohidast-Akrad M, Kollias $\mathrm{G}$, et al. Osteoclasts are essential for TNF-alpha-mediated joint destruction. J Clin Invest 2002;110:1419-27.

32. Goldring SR. Pathogenesis of bone and cartilage destruction in rheumatoid arthritis. Rheumatology 2003;42 Suppl 2:ii11-ii16.

33. Otero M, Goldring MB. Cells of the synovium in rheumatoid arthritis. Chondrocytes. Arthritis Res Ther 2007;9:220.

34. Liu C. The role of ADAMTS-7 and ADAMTS-12 in the pathogenesis of arthritis. Nat Clin Pract Rheumatol 2009;5:38-45.

35. Smolen JS, van der Heijde DM, Aletaha D, Xu S, Han J, Baker D, et al. Progression of radiographic joint damage in rheumatoid arthritis: independence of erosions and joint space narrowing. Ann Rheum Dis 2009;68:1535-40.

36. Burmester GR, Mease P, Dijkmans BAC, Gordon K, Lovell D, Panaccione R, et al. Adalimumab safety and mortality rates from global clinical trials of six immune-mediated inflammatory diseases. Ann Rheum Dis 2009;68;1863-9. 